Discussion The MAPH Method approach to assessing and preventing risk is based on the typically global, interdisciplinary and participatory principles of ergonomics.

\section{TUBERCULOSIS AS AN OCCUPATIONAL DISEASE: KNOWLEDGE, ATTITUDES AND PRACTICES AMONG HEALTHCARE WORKERS OF A PUBLIC HOSPITAL IN LIMA-PERU}

\begin{abstract}
${ }^{1}$ Sandra Albino*, ${ }^{2} J u a n$ Carlos Bazo-Alvarez, ${ }^{1}$ Davide Bosio, ${ }^{3}$ Maria Gamarra, ${ }^{3}$ Frine Samalvides. ' Università Degli Studi di Torino, Turin, Italy; ${ }^{2}$ University College London, London, UK; ${ }^{3}$ Hospital Nacional Cayetano Heredia, Lima, Peru
\end{abstract}

\subsection{6/oemed-2018-ICOHabstracts.947}

Introduction Peru is one of the countries with the highest number of tuberculosis (TB) cases in the Americas with an incidence of $119 \times 100000$ people in the last year. The Stop Tuberculosis Partnership recommends the use of knowledge, attitudes and practices (KAP) instruments to gather valuable information, however there is no previous research in Peru.

Methods An observational cross-sectional study was performed to explore the level of KAP about occupational TB in a healthcare workers group from a public hospital in Lima, during September 2016 to January 2017. We used a validated KAP instrument focused on TB risk of infection and control measures in clinical settings. Descriptive statistics were performed for KAP as well Kendall's Tau-b was used for exploring associations.

Results From 300 participants, 50\% achieved a good level of knowledge and $22.3 \%$ a good performance level on applying control measures. Medical doctors and interns achieved better level of knowledge (81\% and $78 \%)$ while nursing technician and administrative staff had the lowest (19\% and 15\%). Only $19 \%$ of workers from the emergency area achieved a good performance level on the TB Practice scale while more than a half of medical residents (53\%) achieved a bad performance level. A weak positive correlation between the self-perceived TB knowledge and actual TB knowledge was found. (Kendall' s Tau-b $=0.17 ; \mathrm{p}<0.01$ )

Discussion Healthcare workers who labour daily at a high-risk area -especially in emergency area- are not correctly applying control measures to prevent $\mathrm{TB}$, increasing the probability to develop occupational TB. Even though medical doctors achieved better level of knowledge, most of medical residents achieved bad performance level on practices. These results provide baseline information from which control programs should be established. Hospitals' employers should reinforce their methods of ensuring the learning process and the correct implementation of $\mathrm{TB}$ control measures.

\section{DEVELOPMENT OF NATIONAL HEALTH SURVEILLANCE POLICY FOR HEALTHCARE WORKERS}

${ }^{1}$ Zakiah Amir*, ${ }^{2}$ Freda O'Rourke, ${ }^{3}$ Bernie Delaney, ${ }^{2}$ Sibeal Carolan, ${ }^{2}$ Lynda Sisson. ${ }^{1}$ HSE Workplace Health and Wellbeing Unit, Dublin, Ireland; ${ }^{2}$ Occupational Health Department, St John's Hospital, Limerick, Ireland; ${ }^{3}$ Occupational Health Service, Sligo, Ireland

\subsection{6/oemed-2018-ICOHabstracts.948}

Introduction Health surveillance is a system of on-going health checks which allows early identification of ill health and identifies corrective actions needed. There are legislative requirements for health surveillance if risk assessments identify that employees are exposed to certain hazards at workplace. There is a current gap in a standardised health surveillance process and procedures for healthcare workers (HCW) at a national level. The aim of our project is to develop a national health surveillance policy for HCW to address this gap.

Methods Full literature review was conducted to identify the international best practice pertaining to health surveillance in the healthcare setting. Current national legislations outlining the need for health surveillance were also reviewed. Relevant stakeholders including the National Health and Safety Function and national Policy Development team were consulted in the policy development. The Health Service Executive's framework for national policy development was utilised. Drafts of the health surveillance were brought for broad consultations between external stakeholders.

Result Based on the national legislations, a list of hazards requiring health surveillance was identified and categorised under physical/environmental, chemical and biological hazards. A draft policy describing standardised process and procedures of health surveillance for HCW in accordance to evidence-best best practice was developed and brought for further broad consultations.

Discussion This is the first health surveillance policy for healthcare workers developed at a national level. In addition to identifying a list of hazards requiring health surveillance, the policy also outlines specific roles and responsibilities for health surveillance and a standardised process and procedures of health surveillance in a large healthcare organisation. The effectiveness of this national policy depends on how well it is communicated to all local service providers. Its effectiveness in fulfilling the current gap in the current legislations needs to be further evaluated.

\section{THE ROLE OF PERIODIC HEALTH EXAMINATIONS OF HOSPITAL WORKERS IN PREVENTING OCCUPATIONAL CONTACT DERMATITIS IN CROATIA}

M Bubas*. Croatian Institute for Health Protection and Safety at Work, Zagreb, Croatia

\subsection{6/oemed-2018-ICOHabstracts.949}

Introduction Hospital workers, nurses, technicians and doctors are by majority obliged to have periodic medical examinations provided by occupational physicians in occupational health services. It is wide known truth that hospital workers are often burdened with hand eczema. Hence, the purpose of the study was to evaluate the efficacy of periodic health examinations performed by occupational health physicians (OHP) in prevention of occupational contact dermatitis (OCD) in hospital workers.

Methods Study was conducted in two phases during the Horizon 2020 COST Project StanDerm. There were 194 hospital workers employed in clinical hospital over 10 years. Modified EvaHair and NOSQ 2002 questionnaire in Croatian and were used and on-site skin examination performed in both phases to collect data about protective gloves and skin condition. Medical records of periodic health examinations were analysed to assess skin sensitisation.

Results 112 subjects $(57.73 \%)$ wore gloves at work continually for more than one hour per day, 126 (64.94\%) used latex, 25 